äther, Propylalkohol, Butylalkohol und Amylalkohol nachgewiesen und gefunden, dass der letztere der Quantität nach nächst dem Aethylalkohol den Hauptbestandtheil der flüssigen Producte bildet.

In den Destillationsrückständen des Restes befinden sich neben ganz beträchtlichen Mengen von Butyl - und Amylalkohol grössere Quantitäten von Propylalkohol. Die Destillationsrückstände des Branntweins aus den Weintrestern enthalten, wie Chancel schon nachgewiesen hat, ebenfalls Propylalkohol.- (Journ. für prakt. Chemie 1869. S. 191; aus dems. im Jahrb. für Pharmacie. Bd. XXXIII. Heft 2. p. 84.).

C. Schulze.

\title{
Einwirkung von Chlor auf absoluten Alkohol im Sonnenlicht.
}

Franz und Streit machten eine Beobachtung, die bei der Darstellung von Chloralhydrat Berücksichtigung verdienen dürfte. Beim Einleiten des Chlor's in Alkohol fiel zufällig ein Sonnenstrahl auf den Kolben, der den Alkohol in einer ziemlich constanten Temperatur von $62^{\circ} \mathrm{C}$. enthielt. Es trat sofort eine mit schwachem Knall verbundene Detonation ein. Bei fortdauernder Beobachtung erfolgten die Detonationen rascher hintereinander, mit Feuererscheinungen an der Stelle, wo die Gasblasen in den Alkohol eintraten. Dabei erstreckten sich mehrfach die Feuererscheinungen mehre Zolle im Einleitungsrohre hinauf, so dass sie dem Leuchten der Gei ssler'schen Röhren glich. - Zugleich mit diesen Detonationen schwärzte sich der Alkohol bis zur völligen Undurchsichtigkeit und setzte sich aus ihm in der Ruhe ein schwarzes Pulver ab. - Nach und nach steigerte sich nun die Temperatur bis auf $78^{\circ} \mathrm{C}$, während dessen die Erscheinung immer noch beliebig hervorgebracht werden konnte. - Das Phänomen blieb ganz dasselbe, ob directes oder gespiegeltes Licht angewendet wurde. - Magnesiumlicht und die Flamme, die beim Anzünden von Stickgas, welches mit Schwefelkohlenstoffdampf gemisoht ist, entsteht, brachte genau dieselbe Erscheinung hervor. - Dieselbe Wirkung hatte electrisohes Licht und dasjenige, welches auf schmelzendem chlorsauren Kali verbrennender Schwefiel erzeugte. - Das schwarze Pulver, so wie die übelriechenden rothen Producte konnten wegen Zeitmangel nicht untersucht werden. (Journal für prakt. Chemie 108 61; daraus im Jahrb. für Pharmacie. Bd. XXXIII. Heft 2. p. 84.).

C. Schulze. 